\title{
Disparities In Lung Transplantation Before And After Introduction Of The Lung Allocation Score
}

\author{
Keith M. Wille, MD, MSPH ${ }^{1}$, Kathy F. Harrington, PhD, MPH ${ }^{1}$, Joao A. deAndrade, MD ${ }^{1}$, \\ Sonia V. Compton, $\mathbf{M D}^{1}$, Robert A. Oster, $\mathbf{P h D}^{1}$, and Richard A. Kaslow, MD, MPH ${ }^{2}$ \\ ${ }^{1}$ Department of Medicine, School of Public Health, University of Alabama at Birmingham, \\ Birmingham, AL, USA \\ ${ }^{2}$ Department of Epidemiology, School of Public Health, University of Alabama at Birmingham, \\ Birmingham, AL, USA
}

\begin{abstract}
Background-In May 2005 the lung allocation score (LAS) became the primary method for determining allocation of lungs for organ transplantation for those at least 12 years of age in the United States. During the pre-LAS period, black patients were more likely than white patients to become too sick or die while awaiting transplant. The association between gender and lung transplant outcomes has not been widely studied.
\end{abstract}

Methods-Black and white patients $\geq 18$ years of age registered on the UNOS lung transplantation waiting list from January 1, 2000-May 3, 2005 (pre-LAS, n=8765) and May 4, 2005-September 13, 2010 (LAS, n=8806) were included; logistic regression analyses were based on smaller cohorts derived from patients listed in the first 2 years of each era (pre-LAS, $n=2350$, and LAS, $\mathrm{n}=2446$ ) to allow for follow-up time. Lung transplantation was the primary outcome measure. Multivariable analyses were performed within each time period to determine the odds of dying or receiving a lung transplant within three years of listing.

Results-In the pre-LAS era, black patients were more likely than white to become too sick for transplantation or die within three years of wait list registration ( $43.8 \%$ vs. $30.8 \%$; odds ratio [OR] $1.84 ; \mathrm{p}<0.001)$. Race was not associated with death or becoming too sick while listed for transplantation in the LAS era (14.0\% vs. $13.3 \%$; OR 0.93; $\mathrm{p}=0.74)$. Black patients were less likely to undergo transplantation in the pre-LAS era $(56.3 \%$ vs. $69.2 \%$; OR $0.54 ; \mathrm{p}<0.001)$ but not in the LAS era ( $86.0 \%$ vs. $86.7 \%$; OR $1.07 ; \mathrm{p}=0.74)$. Women were more likely than men to die or

Corresponding author: Keith Wille, MD, MSPH, 1900 University Blvd., 422 THT, Birmingham, AL 35294, wille@ uab.edu, Phone: (office) 205-934-7970; (home) 205-823-0228, Fax: 205-975-0671.

Publisher's Disclaimer: This is a PDF file of an unedited manuscript that has been accepted for publication. As a service to our customers we are providing this early version of the manuscript. The manuscript will undergo copyediting, typesetting, and review of the resulting proof before it is published in its final citable form. Please note that during the production process errors may be discovered which could affect the content, and all legal disclaimers that apply to the journal pertain.

Author Contributions: The following author contributions were made for this study: study design and concept (KMW, KFH, RAO, RAK); acquisition, analysis, and interpretation of the data and in writing or revising the article prior to submission (KMW, KFH, JAD, SV, RAO, RAK).

Disclosures: None.

Disclaimer: The Transplant and Waiting List data reported herein have been supplied by the United Network for Organ Sharing as the contractor for the Organ Procurement and Transplantation Network (OPTN). The content of this analysis of the data is the responsibility of the authors alone and does not necessarily reflect the views or policies of the Department of Health and Human Services, nor does mention of trade names, commercial products, or organizations imply endorsement by the U.S Government. No other potential conflicts of interest relating to this study are reported. 
become too sick for transplantation within three years of listing in the LAS era (16.1\% vs. $11.3 \%$; OR $1.58 ; \mathrm{p}<0.001)$, as compared to the pre-LAS era (33.4\% vs. $30.7 \%$; OR $1.19 ; \mathrm{p}=0.08)$.

Conclusion-Racial disparities in lung transplantation have decreased with the implementation of LAS as the method of organ allocation; however, gender disparities may have actually increased in the LAS era.

\section{Keywords}

Lung Transplant; Disparities; LAS; Racial; Gender

\section{Introduction}

The lung allocation score (LAS) was implemented in May 2005 by the Organ Procurement and Transplantation Network (OPTN) as the primary method for allocation of deceased donor lungs for transplantation in persons $\geq 12$ years of age in the United States ${ }^{1}$. Compared to the previous allocation method, LAS was intended to provide a more objective basis for lung allocation than the previous criterion - accrual of time on the transplant waiting list. For lung transplantation, adopting the LAS was consistent with directives from the Department of Health and Human Services calling for organ allocation systems that direct organs to those in most need while minimizing the effects of geography ${ }^{2,3}$.

Before 1995, donor lungs were allocated solely according to time on the waiting list. In 1995, patients with idiopathic pulmonary fibrosis (IPF) received a 90-day credit at listing due to their higher risk of death before transplant; however, organs were still allocated on the basis of waiting list time, without adjustment for disease severity or expected transplant benefit ${ }^{4}$. In both instances, patients referred with advanced lung disease may not have survived the waiting period for an organ, while those with more accrued waiting time but less severe disease would have preferentially undergone transplantation. These systems could also have denied access to patients in certain diagnostic, ethnic, and gender groups. Two retrospective cohort studies examining patients listed for lung transplantation between 1995-2004 found that blacks with chronic obstructive pulmonary disease (COPD) were less likely to undergo transplantation and more likely to die than whites, and black patients with IPF had worse survival after listing ${ }^{5,6}$. These findings are consistent with the differential outcomes reported for other respiratory disorders, including lung cancer ${ }^{7-9}$, asthma ${ }^{10}$, and pulmonary arterial hypertension ${ }^{11}$.

In May 2005, following introduction of the lung allocation score (LAS), the allocation process in the United States changed significantly ${ }^{12}$. The LAS is a numerical value used by the United Network of Organ Sharing (UNOS) to assign relative priority for distributing lungs donated for transplantation within the United States. The LAS is based on survival models that estimate both waitlist and post-transplant survival, and it reflects the net benefit of transplantation. Studies evaluating the LAS suggest that waiting time has decreased, the total number of organs transplanted has increased, waitlist mortality has decreased, and posttransplant survival is unchanged ${ }^{13-17}$. A recent study also found no difference in survival after lung transplantation between whites and non-whites from 2001-2009 ${ }^{18}$. However, it is unclear whether ethnic disparities identified in waitlisted patients before the LAS system was adopted have subsequently improved. Gender disparities have not been assessed widely in this population.

The primary objective of this study was to examine the association between race and lung transplantation both before and after introduction of the LAS. Secondary objectives included examining pre- and LAS associations with gender, and quantifying differences in time to 
transplantation by race or gender. We hypothesized that racial and gender disparities in patients listed for lung transplantation decreased under the new LAS.

\section{Methods}

The LAS was implemented on May 4, 2005. The Organ Procurement and Transplant Network (OPTN) database of UNOS was used to identify patients registered on the waiting list on or before September 4, 2010 during two time periods: pre-LAS (January 1, 2000May 3, 2005) and LAS (May 4, 2005-September 4, 2010). The study population included all white and black non-Hispanic patients aged $\geq 18$ years who were listed for lung transplantation. Race and gender were identified by patients at the time of registration. Patients listed for re-transplantation or multi-organ transplantation were excluded. Patients who underwent living lobar transplantation were excluded. Hispanic patients were excluded from all statistical analyses due to their small patient numbers relative to the number of white and black non-Hispanic patients.

We used a research file with OPTN data available as of December 3, 2010. Variables collected from UNOS included listing date, diagnoses, age, gender, blood type, race, education level, UNOS region, insurance payer, calculated LAS score at time of listing and time of removal for those patients in the LAS era, waiting time accrued, reason for removal from the waiting list, and comorbid illnesses. UNOS data on race, gender, and ethnicity were typically self-reported by listed candidates. Waiting list time was determined as the time between the date a patient was first placed on the waiting list and the date of removal from the list. Date of death was determined using data from the Social Security Master Death File (SSMDF) that were collected by and provided to the investigators by UNOS.

The 11 UNOS regions were aggregated into 4 categories as previously described ${ }^{19}$. Listing diagnoses were grouped as: 1) Group $\mathrm{A}=$ obstructive diseases; 2) Group $\mathrm{B}=$ pulmonary vascular disease; 3) Group C=cystic fibrosis/ immunodeficiency disorders; and 4) Group $\mathrm{D}=$ restrictive diseases. Attained education level was grouped as: 1) none/ grade school; 2) high school/ attended college without a degree; 3) college degree/ higher; and 4) unknown/ unavailable. Insurance provider was grouped as: 1) Medicare, 2) Medicaid, 3) private/ self insurance, and 4) other. To evaluate neighborhood level socioeconomic status, 2000 US Census Bureau data were used to obtain median household income in each patient's residential zip code ${ }^{20}$.

Lung transplant status was grouped as: 1) transplanted=patients with reasons for removal from the waiting list that included transplant, died during transplant, and transplanted at another center; 2) too sick=patients removed from the waiting list with reasons such as too sick or medically unstable for lung transplantation; 3) died=patients who died before lung transplantation;.4) still waiting=patients who were still awaiting transplant; and 5) other=patients whose reasons for removal from the waiting list included refused transplant, transferred to another center, condition improved, living donor, other, and removed in error.

Our primary aim was to test the association of race with receipt of a lung transplant in the pre- vs. LAS era. We also aimed to assess the influence of gender on time to transplantation for each race and gender on the likelihood of receiving a lung transplant in each of the two study periods.

Multiple-variable logistic regression was performed to determine whether race is associated with the likelihood of (a) death or becoming too sick for lung transplantation and (b)

likelihood of lung transplantation within three years of listing. These analyses were restricted to patients listed for the two years between January 1, 2000-December 31, 2001 
(pre-LAS) and May 4, 2005-May 3, 2007 (LAS) to allow for at least three years of followup. Patients categorized as "still waiting" or "other" were excluded from these analyses.

Cox proportional hazards regression models were used to study the association between the variables race and gender and time to death on the waiting list, while controlling for confounders. The models covered the entire pre- and LAS periods to account for differences in follow-up times after wait list registration. Patients who did not die were censored at the date last known alive. The proportional hazards assumption was assessed using log-log survival functions.

To determine which variables to include in the multivariable models, univariate comparisons by the outcome of interest (lung transplantation, or died/too sick for transplantation) were performed for each potential covariate. Patients with missing data on a specific covariate were excluded from analyses involving that covariate. Variables significant ( $\mathrm{p} \unlhd .05$ ) in univariate analysis were retained in the multivariable model for that outcome. Race, gender, and age were retained in all multivariable models.

Differences in continuous variables were tested using 2-group t-tests or Wilcoxon rank sum tests, depending on their distribution. Pearson Chi-square tests or Fisher exact tests were used to test for associations between categorical variables. The following interactions between clinically relevant pairs of co-variates were tested: race and calculated LAS, race and blood type, race and region, race and insurance payer, and gender and calculated LAS.

Statistical tests were 2-sided. Results with $\mathrm{p} \unlhd \mathbf{} .05$ were considered significant. Hazard ratios and adjusted odds ratios were reported for the proportional hazard regression models and logistic regression models, respectively. Statistical analyses were performed using SAS, version 9.2 (SAS Institute, Inc., Cary, NC).

This study was approved by the Institutional Review Board of the University of Alabama at Birmingham, Birmingham, Alabama (N101207004).

\section{Results}

Of 10382 patients registered on the UNOS lung transplantation waiting list in the pre-LAS cohort, 8765 patients were included in the analyses. Of 10682 patients registered in the LAS cohort, 8806 patients were included (Figure 1). Baseline characteristics of the patients who were listed for lung transplantation are shown in Table 1, stratified by race. Table 5 (appendix) shows the same baseline characteristics, stratified by gender. In both the pre-and LAS periods $10.1 \%$ of listed patients were black, and in both periods black patients were significantly younger and more likely to be women.

In the pre-LAS cohort, 374 (42.4\%) black patients and 4364 (55.4\%) white patients who were listed underwent lung transplantation. The frequency of lung transplantation was higher in the LAS cohort for both races, with 554 black (62.2\%) and 5396 white (68.2\%) patients receiving lung transplantation. Black patients were more likely than whites to become too sick for transplant or die while listed in the pre-LAS period (31.5\% vs. $22.4 \%)$, with lower frequencies for both races in the LAS period (12.8\% vs. $11.1 \%)$. Blacks had a higher median LAS both at listing [36.3 (IQR:33.3, 42.6) vs. 35.0 (IQR:32.3, 40.6), $\mathrm{p}<0.001$ ] and at transplantation [40.3 (IQR:35.3, 49.3) vs. 38.2 (IQR:34.0, 46.4), p<0.001]; however, there was no significant difference in median LAS between black and white patients who either died while awaiting transplant or were deemed too sick for transplant [47.2 (IQR:35.3, 87.4) vs. 52.5 (IQR:36.0, 87.8), p=0.41]. Women accounted for $51.3 \%$ of the pre-LAS cohort and $45.5 \%$ of the LAS cohort. Women were younger than men at listing for both the pre-LAS $(48.1 \pm 12.4$ vs. $50.2 \pm 12.3$ years, $\mathrm{p}<0.001)$ and LAS periods $(51.5 \pm 13.2$ 
vs. $55.3 \pm 12.3$ years, $\mathrm{p}<0.001)$. In the pre-LAS period, more women than men were in diagnosis groups A (52.6\% vs. $44.4 \%)$ and B (10.1\% vs. $3.9 \%)$, while fewer women were in groups $\mathrm{C}(14.0 \%$ vs. $14.4 \%)$ and $\mathrm{D}(23.3 \%$ vs. $37.3 \%)$. In the LAS period, more women than men were in diagnostic groups A (44.4\% vs. $34.1 \%)$, B (7.0\% vs. $2.4 \%)$, and C (13.8\% vs. $11.2 \%)$, but fewer women than men in group D (34.9\% vs. $52.4 \%)$.

In the pre-LAS cohort, 2247 (50.0\%) women and 2491 (58.4\%) men who were listed underwent lung transplantation. The frequency of lung transplantation was higher for both genders in the LAS cohort, with 2384 (59.5\%) women and 3566 (74.3\%) men who were listed receiving lung transplantation. Women were more likely than men to become too sick for transplant or die while listed in the pre-LAS period ( $24.1 \%$ vs. $22.5 \%, \mathrm{p}<0.001)$, with lower frequencies for both genders in the LAS period ( $13.0 \%$ vs. $9.9 \%, \mathrm{p}<0.001)$. Women had a lower median LAS at the time of listing [34.5 (IQR:32.2, 39.3) vs. 35.7 (IQR:32.5, 42.2), $\mathrm{p}<0.001]$, at transplantation [37.2 (IQR:33.6, 45.6) vs. 39.0 (IQR:34.4, 47.2), $\mathrm{p}<0.001]$, and at waitlist removal if deemed too sick for transplant or died while awaiting transplant [47.0 (IQR:35.0, 82.4) vs. 63.1 (IQR:37.3, 89.5), p<0.001]. Univariate analyses demonstrated that age, race, gender, blood group, region, diagnostic group, diabetes, insurance payer, and calculated LAS (for post-transplant models) were significantly associated with death while on the waiting list. These characteristics were included in the multivariable analyses. Table 2 shows characteristics of patients on the UNOS Lung Transplantation Waiting List for the initial two years of the pre-LAS and LAS cohorts, by race. Table 6 (appendix) shows these same characteristics, stratified by gender.

To assess the association of race with receipt of lung transplantation, several adjusted analyses were performed to control for factors associated with transplantation or death while on the waiting list (Table 3). The first analysis demonstrated that the odds of death or becoming too sick for transplantation within three years of listing to be significantly higher for black vs. white patients in the pre-LAS cohort (43.8\% vs. 30.8\%; OR 1.84; $<<0.001$ ) but not in the LAS cohort (14.0\% vs. $13.3 \%$; OR 0.93; $\mathrm{p}=0.74)$.

After adjusting for relevant covariates, we found that black patients were significantly less likely than white patients to receive lung transplantation within three years of listing in the pre-LAS period (56.3\% vs. $69.2 \%$; OR 0.54; $\mathrm{p}<0.001)$ but not in the LAS period $(86.0 \%$ vs. $86.7 \%$; OR 1.07; $\mathrm{p}=0.74$ ). Interaction between (a) race and gender and (b) race and initial calculated LAS were not significant in the multivariable analyses and were excluded from the final model.

Altogether, women and men underwent lung transplantation more often in the LAS era (2118 of $2446,86.6 \%$ ) compared to the pre-LAS era (1598 of 2350, 68.0\%), and fewer candidates were removed because of death or illness in the LAS era (328 of 2446, 13.4\%) compared to the pre-LAS era (752 of 2350, 32.0\%). (Table 4) After adjusting for covariates, women were more likely than men to become too sick for lung transplantation or die within three years of listing in the LAS period ( $16.1 \%$ vs. $11.3 \%$; OR 1.58 ; $\mathrm{p}<0.001)$, but this difference was less significant in the pre-LAS period ( $33.4 \%$ vs. $30.7 \%$; OR 1.19 ; $\mathrm{p}=0.08$ ). Women were also significantly less likely than men to undergo lung transplantation in the LAS period (83.9\% vs. 88.7\%; OR 0.63; p<0.001) but not in the pre-LAS period (66.6\% vs. 69.3\%; OR 0.84; $\mathrm{p}=0.08$ ). Interactions between (a) gender and race; (b) gender and diagnostic group; and (c) gender and initial calculated LAS were not significant in the multivariate analyses and were excluded from the final model. The trends observed for race and gender were unchanged when only those patients who died (as opposed to those who either died or were too sick for transplant) were included in logistic regression models. 
Time to death by race was assessed over the entire pre- and LAS periods by proportional hazards models with adjustment for other predictor variables. Black patients listed in the pre-LAS period had a higher risk of wait-list removal for death compared to white patients [hazard ratio (HR) 1.18; 95\%CI 0.99-1.40; $\mathrm{p}=0.06$ ]. Mortality rates did not differ significantly by race in the LAS period (HR $0.83 ; 95 \%$ CI $0.62-1.10 ; \mathrm{p}=0.18$ ). After controlling for multiple predictors, gender was associated with time to death in both the preLAS (HR 1.12; 95\%CI 1.01-1.25; $\mathrm{p}=0.04$ ) and the LAS cohort (HR 1.53; 95\%CI 1.28-1.82; $\mathrm{p}<0.001)$. Proportional hazards assumptions were satisfied for all time to death models that were stratified separately by race and gender.

\section{Discussion}

Since the system for allocating lung transplants was implemented in 2005, the adoption of objective measures of disease severity (LAS) rather than waiting time as the basis for allocation has had several notable effects ${ }^{21}$. Studies have reported decreases in wait list registrations and wait times for transplantation, a decrease in wait list mortality, a change in the distribution of diagnoses receiving transplantation, and no significant survival difference between the pre- and LAS eras ${ }^{13-17,22-24}$. These achievements are consistent with many of the goals behind the creation of the new allocation system. One of the aims in adopting a more objective system like the LAS was to eliminate potential biases inherent within the previous allocation system ${ }^{2}$. This goal was achieved in part for liver transplantation in 2002 with adoption of the MELD score allocation system, which has been shown to reduce racial but not gender disparities in terms of risk of death while on the waiting list and likelihood of liver transplantation ${ }^{25}$. To our knowledge, ours was the first study to assess changes in raceor gender-based disparities in access to lung transplantation following implementation of the LAS.

We found that before the LAS was implemented black race was associated with both increased risk of death or becoming too sick for lung transplantation and decreased likelihood of lung transplantation within 3 years of wait list registration. Following implementation of the LAS, differences between black and white recipients were no longer observed. These results suggest that the LAS has had a positive impact on racial disparities in access to lung transplantation. In contrast, gender remained associated with increased risk of death in the LAS era, although women were less likely to undergo lung transplantation in that cohort. Gender differences in lung transplantation may result from patient-specific factors that affect access to suitable organs, such as smaller stature or elevated panel of reactive antibody (PRA) levels; alternatively, there may be other variables not included in the current LAS that are important in explaining this disparity.

Our findings in the pre-LAS cohort are similar to those previously reported for patients awaiting lung transplantation. In a 2006 single-center study, Lederer et al. ${ }^{26}$ first observed that black and Hispanic patients had a significantly increased risk of death compared to other ethnic groups. Survival differences were attributed to several factors, including differences in rates of disease progression, exercise capacity, access to medical care, and other socioeconomic factors. A follow-up study by the same group using UNOS/OPTN data for IPF patients on the transplant waiting list from 1995-2003 found that age-adjusted mortality rates were $24 \%$ and $29 \%$ higher for blacks and Hispanics, respectively, as compared to non-Hispanic whites ${ }^{5}$. This disparity was partly explained by worse lung function at the time of listing, although significant differences persisted. A third study examining racial differences in wait list outcomes for patients with COPD listed from 19952004 found that blacks were less likely to undergo transplantation (adjusted HR 0.83; $\mathrm{p}=0.03$ ) and had a greater risk of dying (unadjusted HR $1.31 ; 95 \% \mathrm{CI}, 1.05-1.63 ; \mathrm{p}=0.02)^{6}$. These studies examined wait list patients exclusively during the pre-LAS era; our aim was to 
extend the analysis of these identified disparities to the LAS era for comparison with the earlier period. Unlike prior studies, we chose to include all diagnostic groups in order to maximize study power and assess the overall effect of the LAS on disparities in lung transplantation. More recently, Liu et al. found that, when compared to the historical transplant era (1987-2000), there was no significant difference in lung transplant survival between whites and nonwhites in the modern era (2001-2009); however, the effect of the LAS was not specifically examined, and all racial groups not classified as white were included in the nonwhite category 18 .

The strengths of this study include the large number of transplant candidates, use of a national database, and the availability of several variables that may influence transplant outcomes. This study also has several limitations. First, we utilized the UNOS database, and the accuracy of these findings depends on correct data reporting from individual transplant centers. Evolution of the UNOS database over time and changes in the type of data collected, however, have resulted in missing data. While lower serum albumin levels, for example, were associated with higher mortality in wait list patients with idiopathic interstitial pneumonia ${ }^{27}$, we excluded this variable from analyses because data were missing in the LAS cohort. We decided to exclude missing data from analysis rather than perform imputation methods given changes to the database over time and potential for introduction of bias. Use of SSMDF data provided by UNOS may have resulted in some misclassification of demographic factors (as UNOS data is either self-reported or collected by each transplant center) and vital status; however, centers are required to report candidate deaths to UNOS within 24 hours of notification, and UNOS regularly updates their death records from the SSMDF. Additionally, as transplant centers closely monitor listed candidates for clinical deterioration, we reasoned that use of a UNOS data file generated 3 months after the end of the study period would have minimal misclassification, as delisted or deceased patients should be reported to UNOS. Considering the high numbers of patients in both cohorts and relatively few missing data for the predictor variables in the final multivariable models, missing values would not likely have appreciably altered the results. Moreover, complete data were available on race and gender, the variables of primary interest. Still, our findings should be further validated in an independent cohort of lung transplant candidates. Logistic regression models were used to predict the probability of an event by a specified time, with anticipated loss of information as compared to time-to-event methods utilizing censoring methods. The odds ratios, as compared to risk ratios, may overestimate the effect size for non-rare outcomes ${ }^{28}$; however, the study's aim was to investigate LAS-disparity associations, rather than to report the absolute strengths of any associations found.

One potential limitation of the LAS model, and this study, is the method of disease classification, particularly less common lung diseases. Regardless of the underlying diagnosis, patients in the LAS model are ultimately classified into one of four disease categories - obstructive diseases, pulmonary vascular diseases, cystic fibrosis/ immunodeficiency disorders, or restrictive diseases—based on the more common transplant indications ${ }^{24}$. Black patients were notably concentrated in diagnostic groups A and D, reflecting the racial distribution of diseases for which transplant is considered. As underlying diagnosis has been shown to predict waitlist survival ${ }^{29-31}$ and the racial distribution associated with each diagnostic group varies, it is possible that using this classification scheme biased the observed relationships. Nunley et al. recently demonstrated that a lower LAS was associated with increased likelihood of survival to transplantation, although sample size limited any conclusions regarding race and gender disparities ${ }^{32}$.

Another limitation pertains to changes in the database and method of lung allocation during the course of the study period. The LAS typically varies with time, often increasing as 
disease progresses. Because LAS at the time of listing correlated closely with the time of wait list removal, only the LAS at listing was used for the multivariate models. Furthermore, there may be important predictors of outcome that are not captured by UNOS, or other variables like a center's transplant volume or socioeconomic status, that were not included in our analyses but may affect the findings ${ }^{33,34}$. A fourth limitation relates the possibility of failing to identify outcome differences between groups in the LAS era based on sample size (type 2 error). The choice to limit the logistic regression analyses to patients listed in the initial 2 years of each era (with a 3-year follow-up period) reduced the available sample size for analysis; however, this was felt to be necessary because of longer waiting times to transplantation in the pre-LAS era and the desire to capture a sufficient number of outcomes. Finally, our study evaluated lung transplantation among patients already listed for this procedure; there may be important racial or gender differences in patterns of referral or access to transplantation that are not captured in our analysis.

Despite differences in the important baseline characteristics of black and white patients listed for lung transplantation, race was not associated with death on the waiting list or receipt of lung transplantation in the LAS era. These findings clearly differ from those before implementation of the LAS, when black patients had a higher risk of death or becoming too sick while on the waiting list and a lower likelihood of receiving lung transplantation. Gender differences may persist despite LAS implementation; women were less likely to undergo transplantation in the LAS era, although risk of death was similar for men and women. Additional studies examining potential explanations of these findings and whether further modifications to the LAS may lessen such disparities are warranted. In summary, introduction of the LAS for allocation of donor lungs appears to have reduced racial disparities; however, further investigation should focus not only on longer-term outcomes and quality of life, but also the impact of the LAS method on gender disparities in lung transplantation.

\section{Acknowledgments}

We thank Bruce Shepperson at UNOS for his assistance with data management and David Lederer MD, MS and Ashita Tolwani, M.D, M.Sc. for their critical review of the manuscript.

Funding: This work is supported in part by Health Resources and Services Administration contract 231-00-0115, the UAB Center for Clinical and Translational Science (CCTS) grant TL1 TR000167 (RAO and RAK), and funding from the UAB Comprehensive Transplant Institute.

\section{Appendix 1}

Predictors of Mortality in the LAS Model ${ }^{12}$ :

A. Wait List Model

a. Severity of Disease

i. $\quad$ FVC

ii. PA systolic *

iii. $\mathrm{O} 2$ required at rest

iv. $\begin{aligned} & \text { Ventilator } \\ & \text { requirement }\end{aligned}$

b. Physiologic Reserve
i. Age *
ii. $\mathrm{BMI}$
iii. Diabetes

\section{A. Post-Transplant Model}

a. Severity of Disease
i. $\quad \mathrm{FVC}^{*}$
ii. $\quad \mathrm{PCW}$ pressure
iii. Ventilator

b. Physiologic Reserve
i. Age
ii. Creatinine
iii. Functional status 
iv. Functional Status

c. Diagnoses

v. 6-minute walk

c. Diagnoses

Effect differs by diagnosis group

\section{Appendix 2}

Options Available To Transplant Centers For Entering Data Regarding Transplant Status:

\begin{tabular}{ll}
\hline $\mathbf{1}$ & Transplanted (includes "emergency transplant" and "died during transplant") \\
$\mathbf{2}$ & Still Waiting For Transplant \\
$\mathbf{3}$ & Too Sick For Lung Transplant \\
$\mathbf{4}$ & Died \\
$\mathbf{5}$ & Condition Improved \\
$\mathbf{6}$ & Transferred To Another Center \\
$\mathbf{7}$ & Living Donor Transplant \\
$\mathbf{8}$ & Refused Transplant \\
$\mathbf{9}$ & Other \\
\hline
\end{tabular}

\section{Appendix 3}




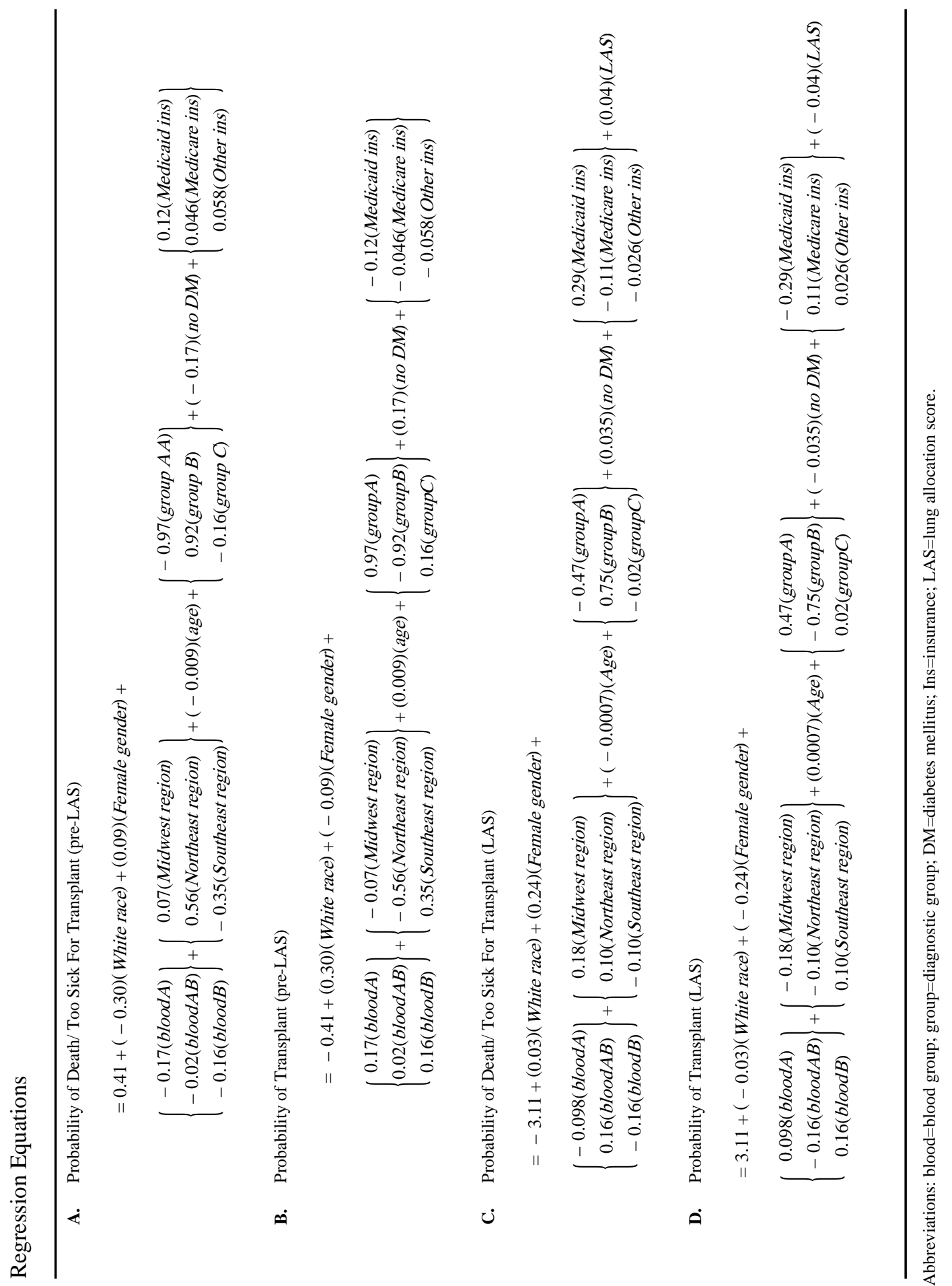




\section{References}

1. Eberlein M, Garrity ER, Orens JB. Lung allocation in the United States. Clin Chest Med. 2011 Jun; 32(2):213-222. [PubMed: 21511084]

2. Organ Procurement Transplantation Network. Health Resources and Services Administration, HHSFinal rule. Fed Regist. 1999 Oct 20; 64(202):56650-56661. [PubMed: 11010703]

3. Egan TM, Kotloff RM. Pro/Con debate lung allocation should be based on medical urgency and transplant survival and not on waiting time. Chest. 2005 Jul; 128(1):407-415. [PubMed: 16002964]

4. Davis SQ, Garrity ER Jr. Organ allocation in lung transplant. Chest. 2007 Nov; 132(5):1646-1651. [PubMed: 17998365]

5. Lederer DJ, Arcasoy SM, Barr RG, et al. Racial and ethnic disparities in idiopathic pulmonary fibrosis: A UNOS/OPTN database analysis. Am J Transplant. 2006 Oct; 6(10):2436-2442. [PubMed: 16869805]

6. Lederer DJ, Benn EK, Barr RG, et al. Racial differences in waiting list outcomes in chronic obstructive pulmonary disease. Am J Respir Crit Care Med. 2008 Feb 15; 177(4):450-454. [PubMed: 18006881]

7. Bach PB, Cramer LD, Warren JL, Begg CB. Racial differences in the treatment of early-stage lung cancer. N Engl J Med. 1999 Oct 14; 341(16):1198-1205. [PubMed: 10519898]

8. Gadgeel SM, Severson RK, Kau Y, Graff J, Weiss LK, Kalemkerian GP. Impact of race in lung cancer: analysis of temporal trends from a surveillance, epidemiology, and end results database. Chest. 2001 Jul; 120(1):55-63. [PubMed: 11451816]

9. Wisnivesky JP, McGinn T, Henschke C, Hebert P, Iannuzzi MC, Halm EA. Ethnic disparities in the treatment of stage I non-small cell lung cancer. Am J Respir Crit Care Med. 2005 May 15; 171(10): 1158-1163. [PubMed: 15735053]

10. Grant EN, Lyttle CS, Weiss KB. The relation of socioeconomic factors and racial/ethnic differences in US asthma mortality. Am J Public Health. 2000 Dec; 90(12):1923-1925. [PubMed: 11111268]

11. Kawut SM, Horn EM, Berekashvili KK, et al. New predictors of outcome in idiopathic pulmonary arterial hypertension. Am J Cardiol. 2005 Jan 15; 95(2):199-203. [PubMed: 15642552]

12. Egan TM, Murray S, Bustami RT, et al. Development of the new lung allocation system in the United States. Am J Transplant. 2006; 6(5 Pt 2):1212-1227. [PubMed: 16613597]

13. Gries CJ, Mulligan MS, Edelman JD, Raghu G, Curtis JR, Goss CH. Lung allocation score for lung transplantation: impact on disease severity and survival. Chest. 2007 Dec; 132(6):1954-1961. [PubMed: 18079228]

14. Kozower BD, Meyers BF, Smith MA, et al. The impact of the lung allocation score on short-term transplantation outcomes: a multicenter study. J Thorac Cardiovasc Surg. 2008 Jan; 135(1):166171. [PubMed: 18179935]

15. Lingaraju R, Blumenthal NP, Kotloff RM, et al. Effects of lung allocation score on waiting list rankings and transplant procedures. J Heart Lung Transplant. 2006 Sep; 25(9):1167-1170. [PubMed: 16962482]

16. McCue JD, Mooney J, Quail J, Arrington A, Herrington C, Dahlberg PS. Ninety-day mortality and major complications are not affected by use of lung allocation score. J Heart Lung Transplant. 2008 Feb; 27(2):192-196. [PubMed: 18267226]

17. Merlo CA, Weiss ES, Orens JB, Impact of U.S, et al. Lung Allocation Score on survival after lung transplantation. J Heart Lung Transplant. 2009 Aug; 28(8):769-775. [PubMed: 19632571]

18. Liu V, Weill D, Bhattacharya J. Racial disparities in survival after lung transplantation. Arch Surg. 2011 Mar; 146(3):286-293. [PubMed: 21422359]

19. Moylan CA, Brady CW, Johnson JL, Smith AD, Tuttle-Newhall JE, Muir AJ. Disparities in liver transplantation before and after introduction of the MELD score. JAMA : the journal of the American Medical Association. 2008; 300(20):2371-2378. [PubMed: 19033587]

20. United States. Bureau of the Census. State \& County QuickFacts. Washington, D.C: The Bureau; 2000. http://quickfacts.census.gov/qfd/.

21. Takahashi SM, Garrity ER. The impact of the lung allocation score. Semin Respir Crit Care Med. 2010 Apr; 31(2):108-114. [PubMed: 20354924] 
22. Chen H, Shiboski SC, Golden JA, et al. Impact of the lung allocation score on lung transplantation for pulmonary arterial hypertension. Am J Respir Crit Care Med. 2009 Sep 1; 180(5):468-474. [PubMed: 19520906]

23. McCurry KR, Shearon TH, Edwards LB, et al. Lung transplantation in the United States, 19982007. Am J Transplant. 2009 Apr; 9(4 Pt 2):942-958. [PubMed: 19341417]

24. Yusen RD, Shearon TH, Qian Y, et al. Lung transplantation in the United States, 1999-2008. Am J Transplant. 2010 Apr; 10(4 Pt 2):1047-1068. [PubMed: 20420652]

25. Moylan CA, Brady CW, Johnson JL, Smith AD, Tuttle-Newhall JE, Muir AJ. Disparities in liver transplantation before and after introduction of the MELD score. JAMA. 2008 Nov 26; 300(20): 2371-2378. [PubMed: 19033587]

26. Lederer DJ, Caplan-Shaw CE, O'Shea MK, et al. Racial and ethnic disparities in survival in lung transplant candidates with idiopathic pulmonary fibrosis. Am J Transplant. 2006 Feb; 6(2):398403. [PubMed: 16426327]

27. Zisman DA, Kawut SM, Lederer DJ, et al. Serum albumin concentration and waiting list mortality in idiopathic interstitial pneumonia. Chest. 2009 Apr; 135(4):929-935. [PubMed: 19017875]

28. Davies HT, Crombie IK, Tavakoli M. When can odds ratios mislead? BMJ. 1998 Mar 28; 316(7136):989-991. [PubMed: 9550961]

29. De Meester J, Smits JM, Persijn GG, Haverich A. Listing for lung transplantation: life expectancy and transplant effect, stratified by type of end-stage lung disease, the Eurotransplant experience. J Heart Lung Transplant. 2001 May; 20(5):518-524. [PubMed: 11343978]

30. Hosenpud JD, Bennett LE, Keck BM, Edwards EB, Novick RJ. Effect of diagnosis on survival benefit of lung transplantation for end-stage lung disease. Lancet. 1998 Jan 3; 351(9095):24-27. [PubMed: 9433425]

31. Ouwens JP, Groen H, TenVergert EM, Koeter GH, de Boer WJ, van der Bij W. Simulated waiting list prioritization for equitable allocation of donor lungs. J Heart Lung Transplant. 2002 Jul; 21(7): 797-803. [PubMed: 12100906]

32. Nunley DR, Bauldoff GS, Holloman CH, Pope-Harman A. The lung allocation score and survival in lung transplant candidates with chronic obstructive pulmonary disease. Lung. 2009 Nov-Dec; 187(6):383-387. [PubMed: 19806401]

33. Quon BS, Psoter K, Mayer-Hamblett N, Aitken ML, Li CI, Goss CH. Disparities in access to lung transplantation for patients with cystic fibrosis by socioeconomic status. Am J Respir Crit Care Med. 2012 Nov 15; 186(10):1008-1013. [PubMed: 22983958]

34. Weiss ES, Allen JG, Meguid RA, et al. The impact of center volume on survival in lung transplantation: an analysis of more than 10,000 cases. Ann Thorac Surg. 2009 Oct; 88(4):10621070. [PubMed: 19766782] 


\section{Pre-LAS Cohort}

10382 Patients registered on the UNOS Lung transplantation waiting list (January 1, 2000 - May 3, 2005)

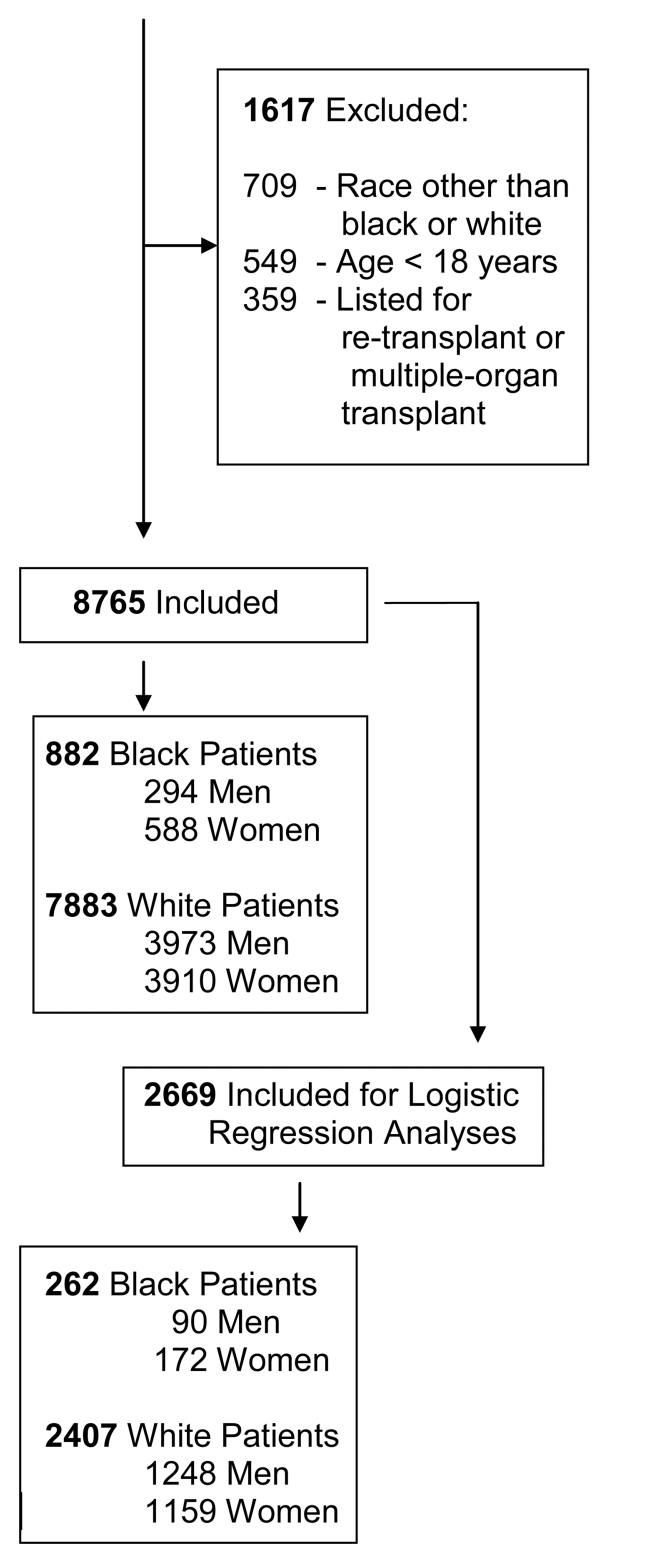

\section{LAS Cohort}

10682 Patients registered on the UNOS Lung transplantation waiting list (May 4, 2005 - September 4, 2010)
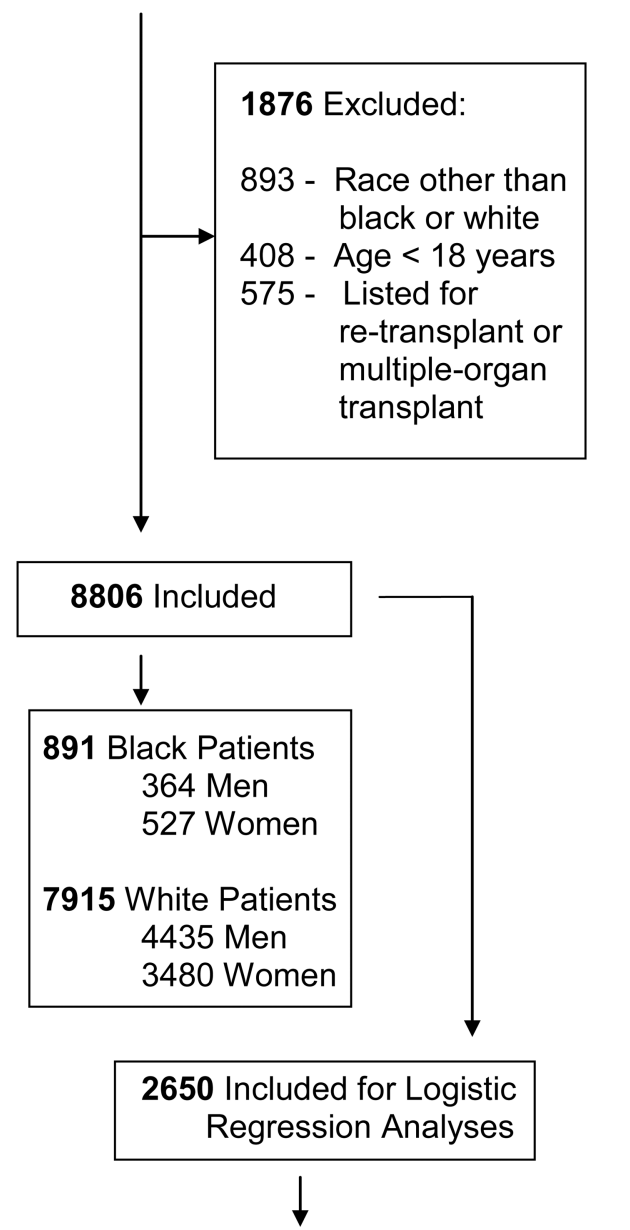

262 Black Patients 116 Men 146 Women

2388 White Patients 1320 Men 1068 Women

Figure 1.

Patients Registered on the UNOS Lung Transplantation Waiting List Before and After LAS 


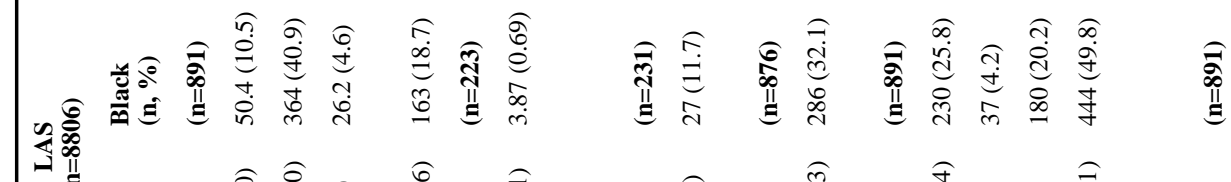
要

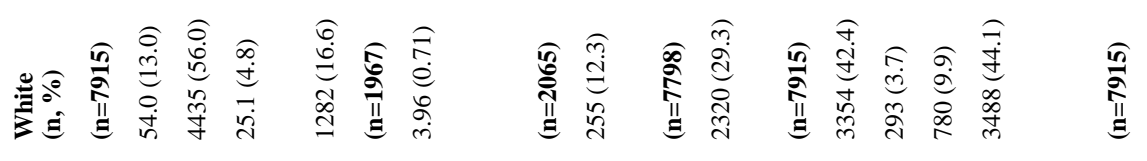

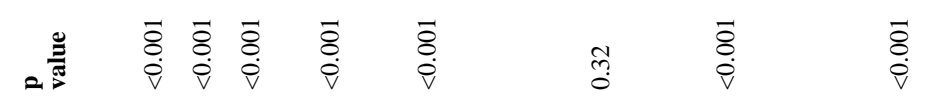

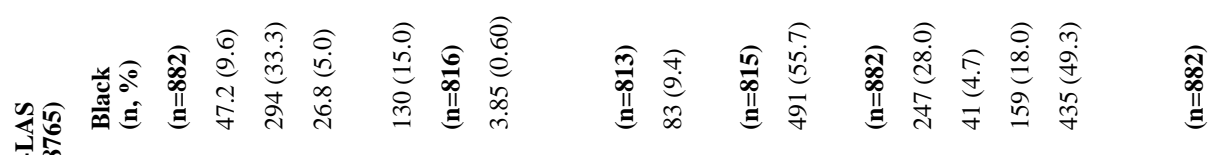

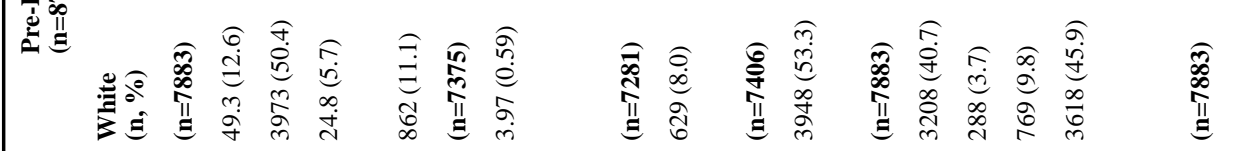

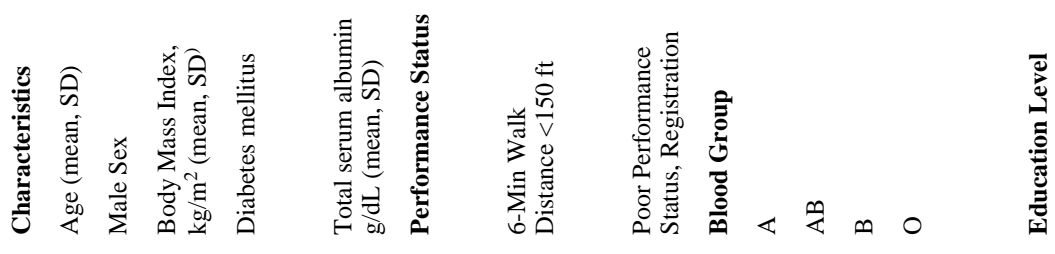




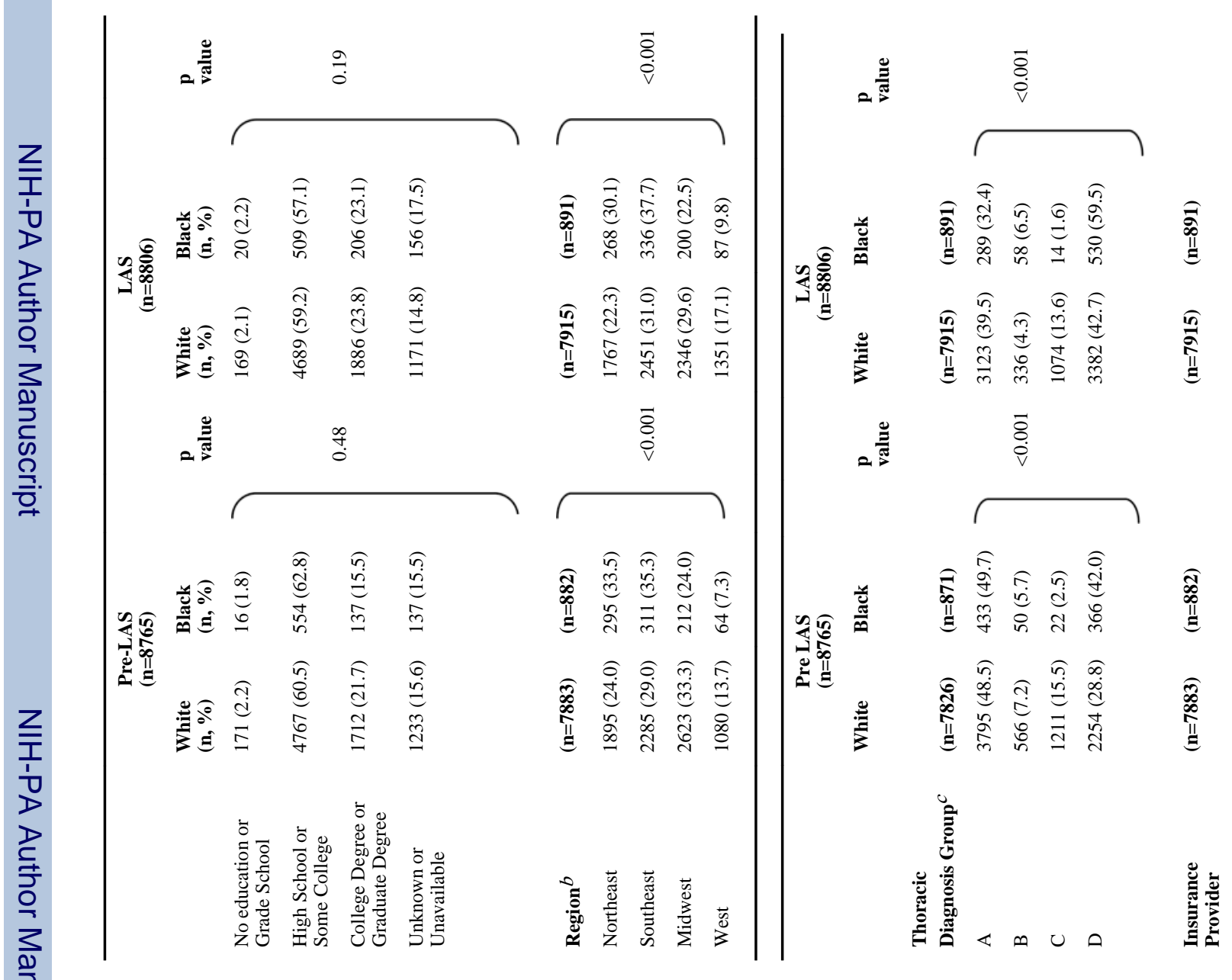




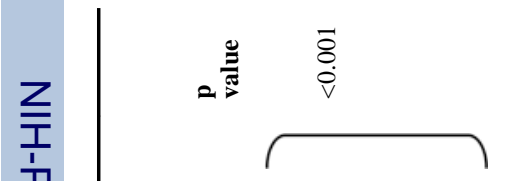

Z

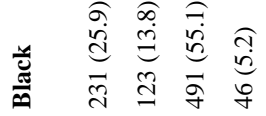
唋

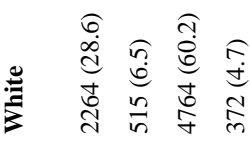

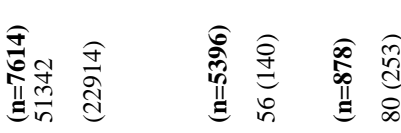

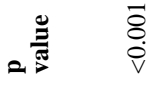
$\stackrel{\bar{\Xi}}{\dot{\nabla}}$
o.

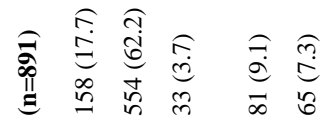

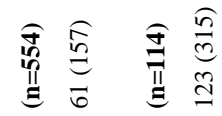

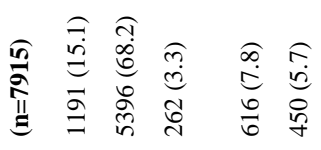
$\stackrel{\overrightarrow{8}}{\dot{\nabla}}$

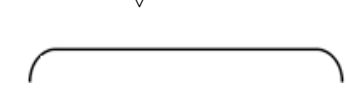

$\stackrel{\infty}{8}$

(6)

로을

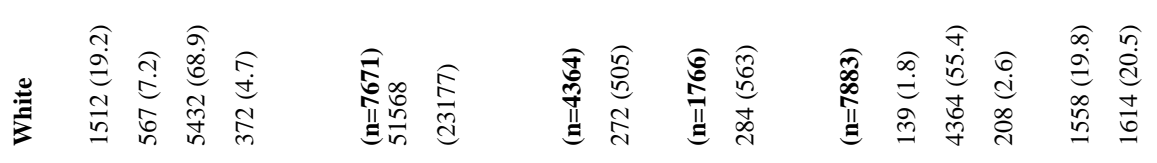

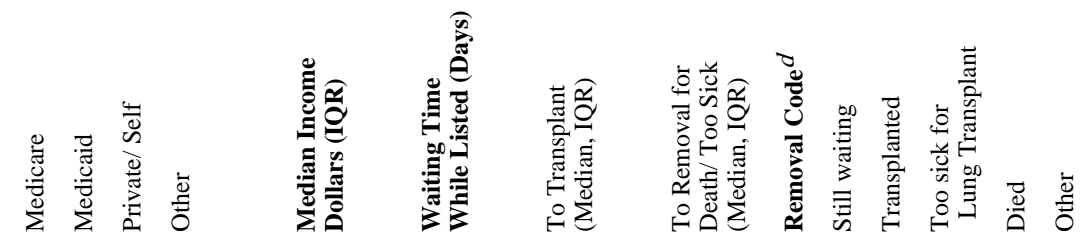

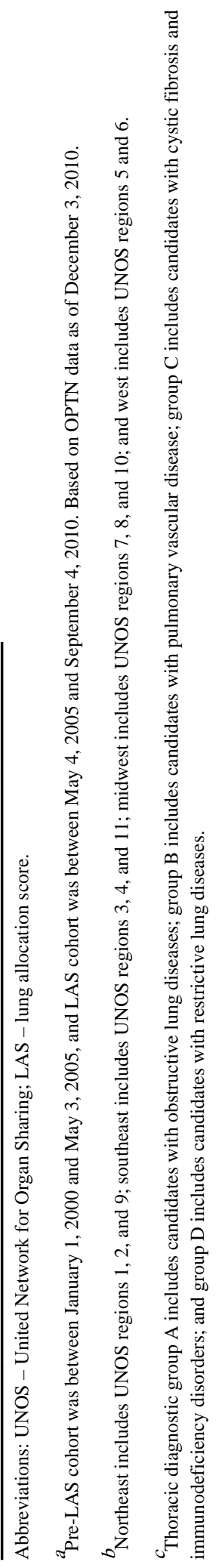




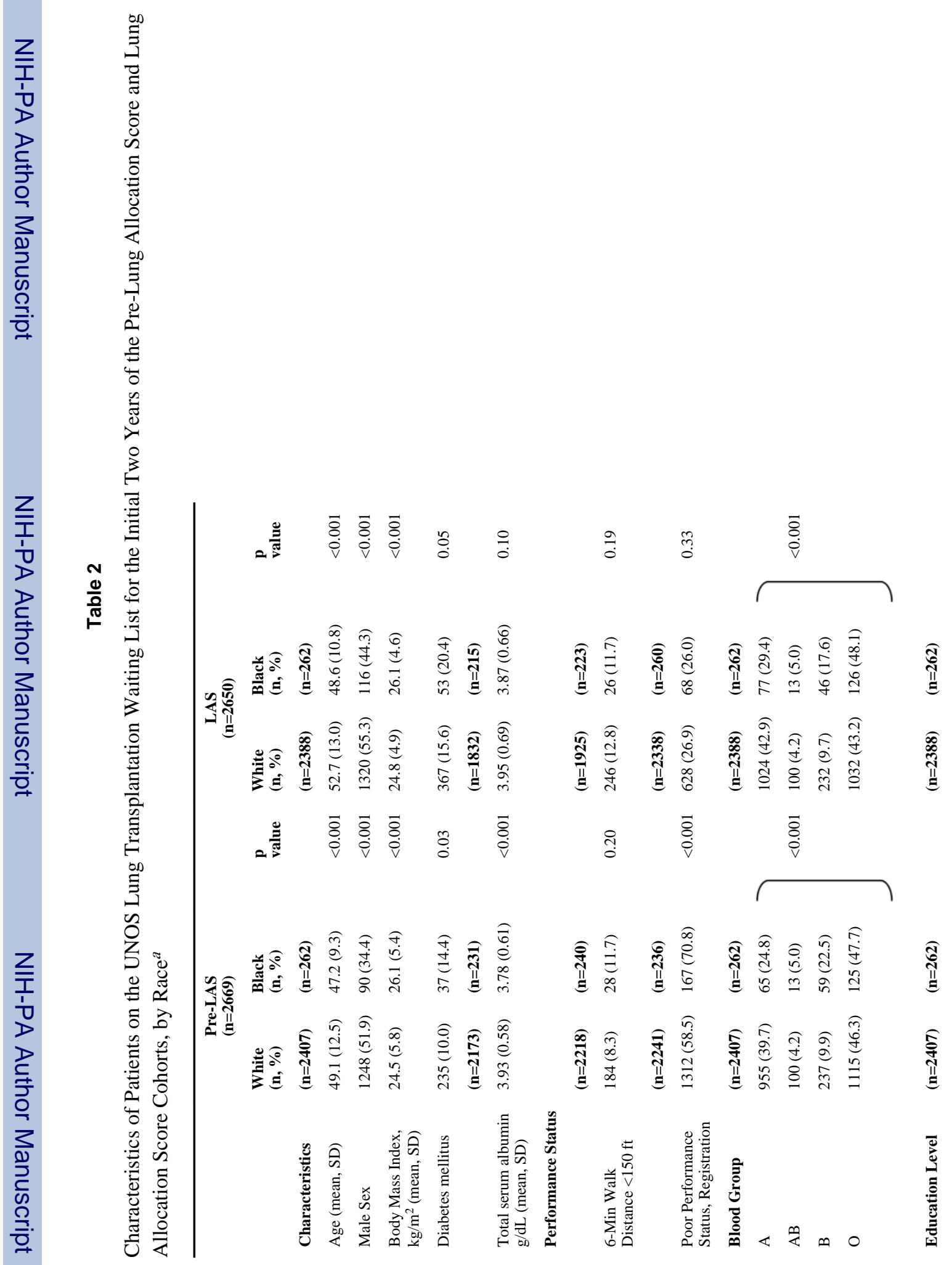


$=\stackrel{\overline{3}}{3}$

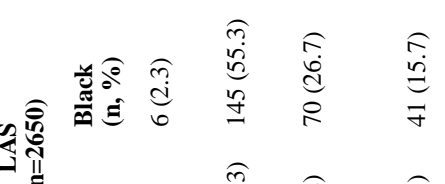

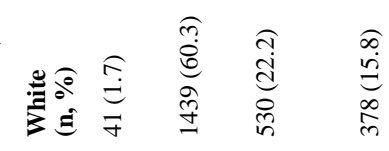

2

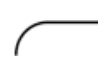

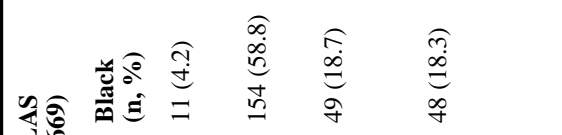

ง

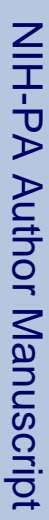

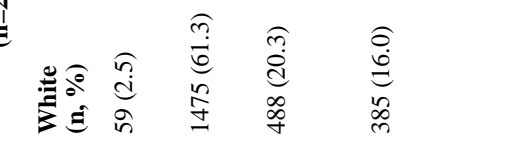

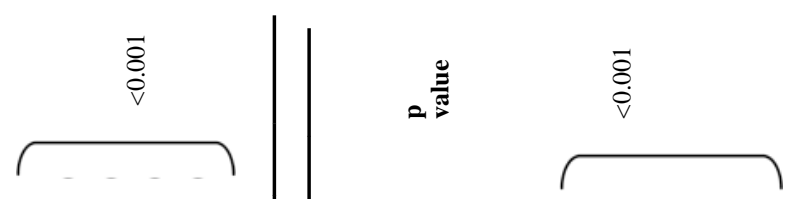

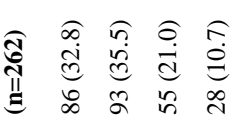

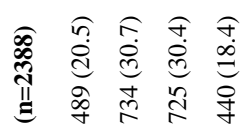

过

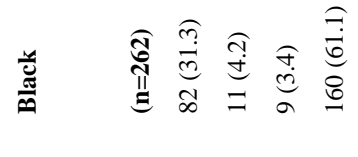

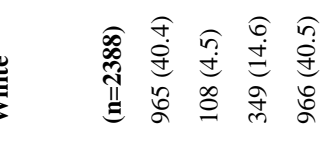

2

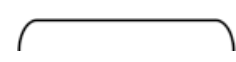

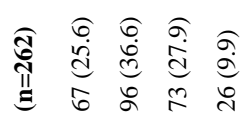

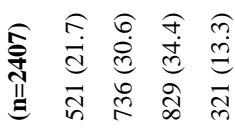

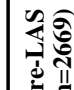

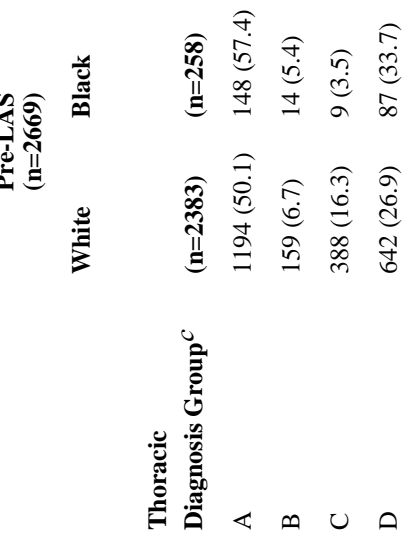

.

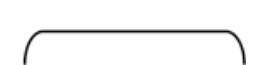

象




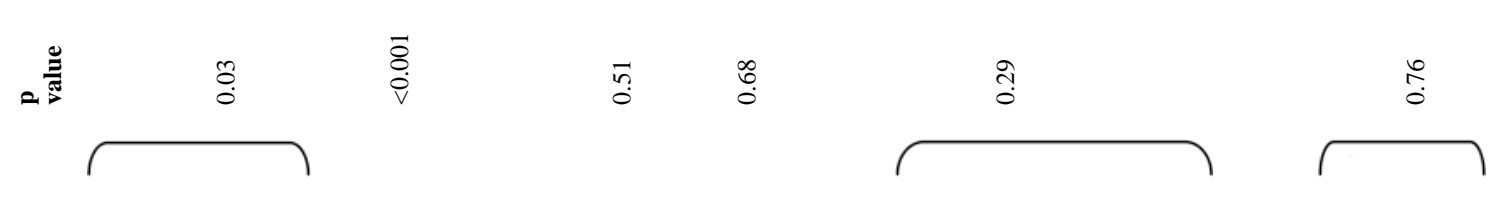

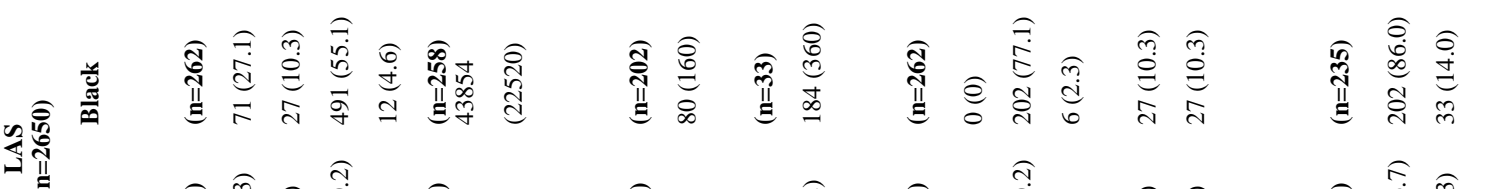

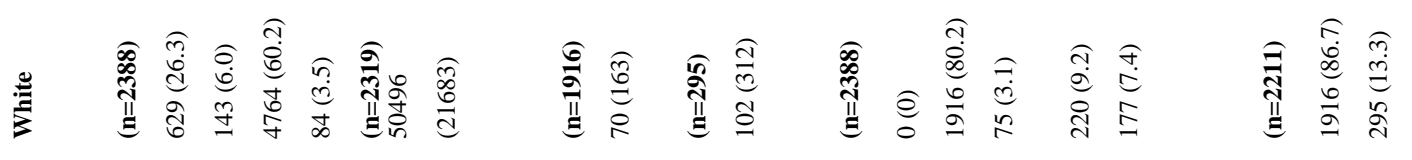

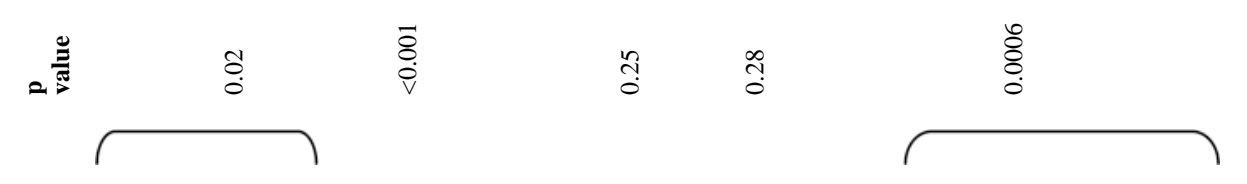

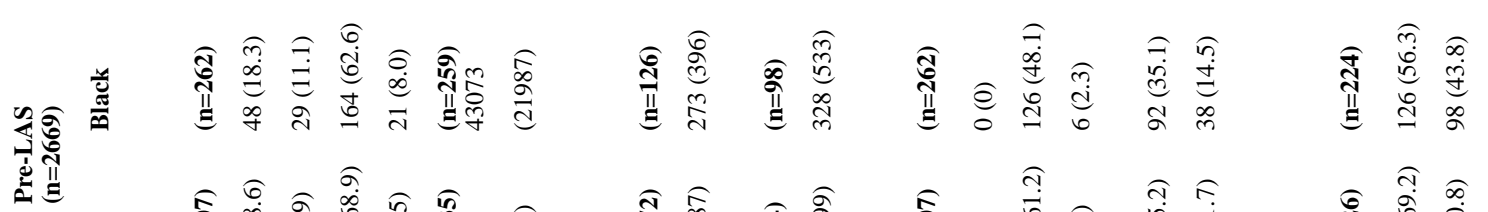

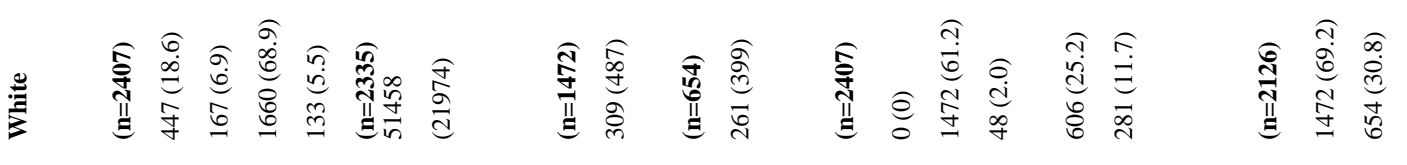

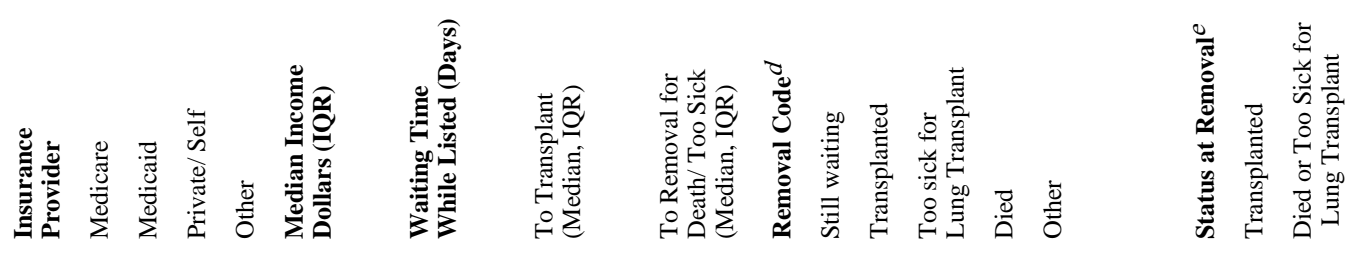




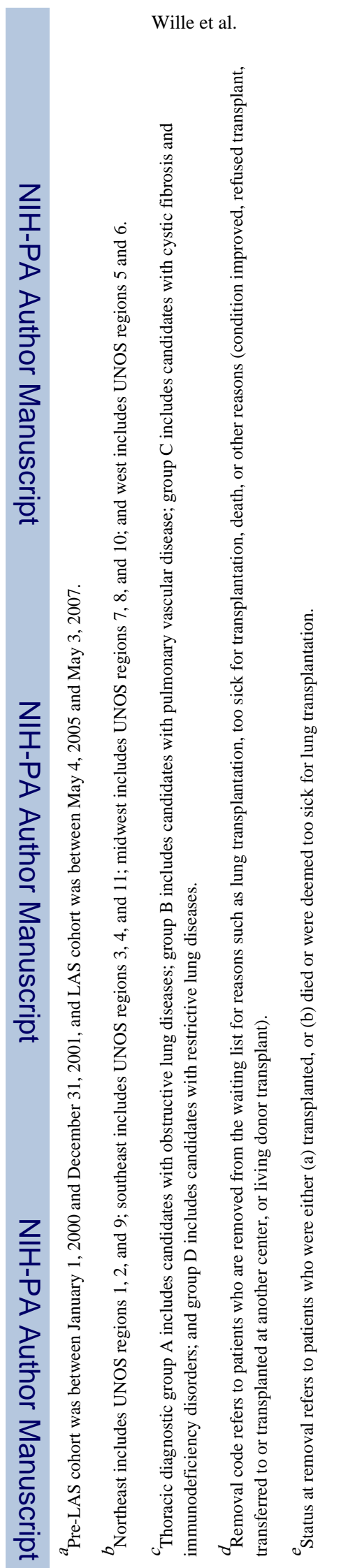

J Heart Lung Transplant. Author manuscript; available in PMC 2014 July 01. 


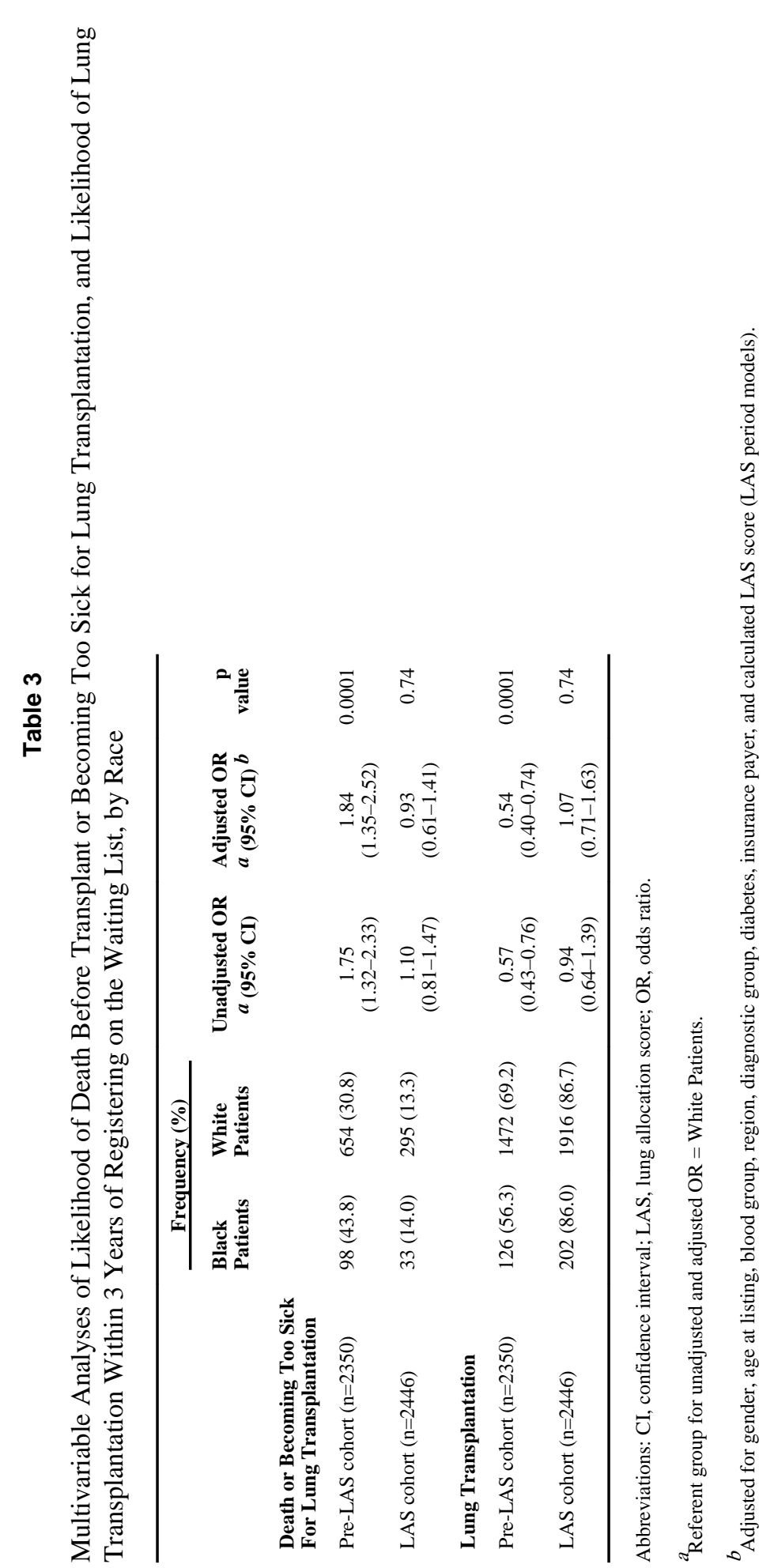

J Heart Lung Transplant. Author manuscript; available in PMC 2014 July 01. 


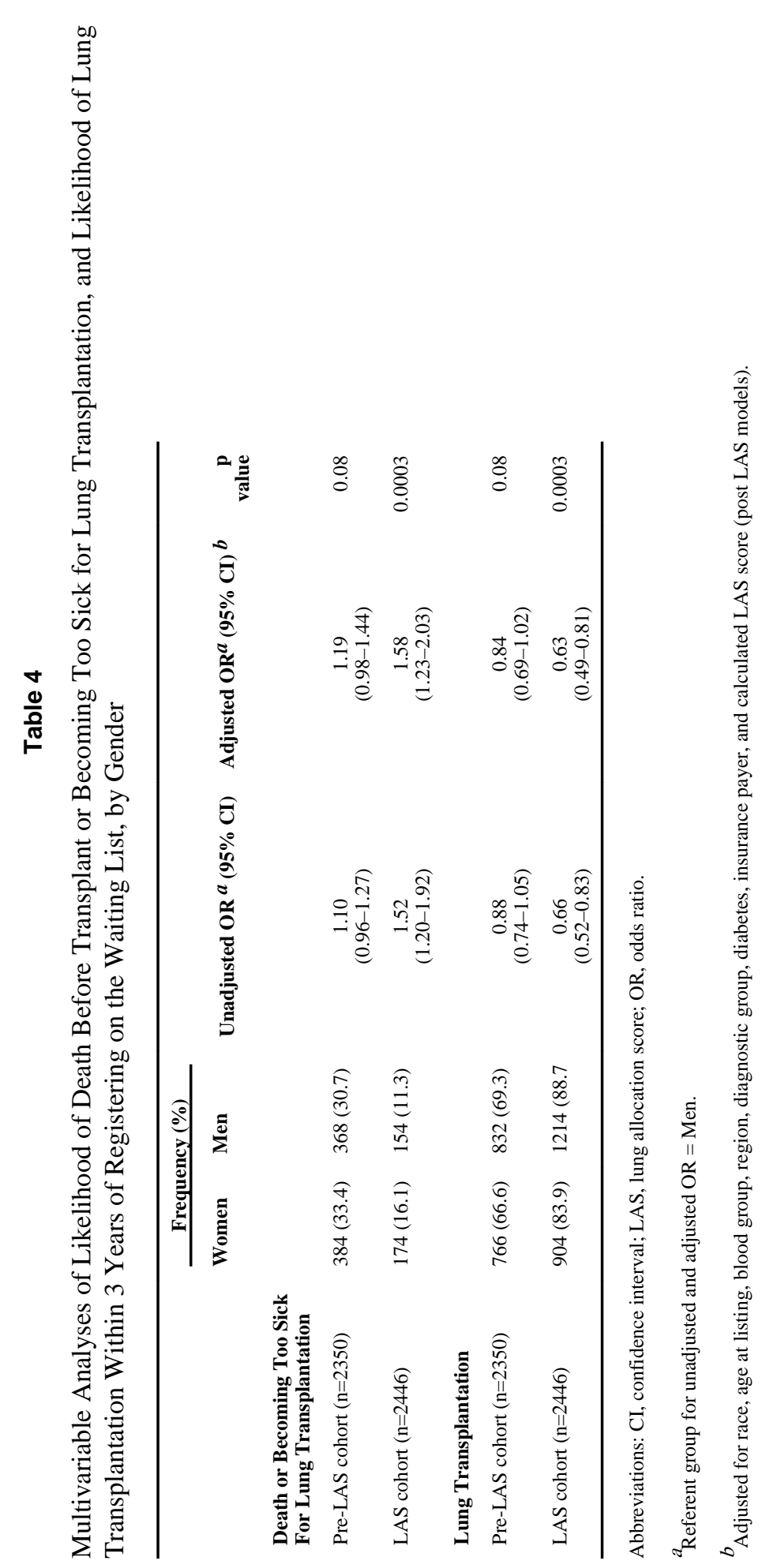

J Heart Lung Transplant. Author manuscript; available in PMC 2014 July 01. 


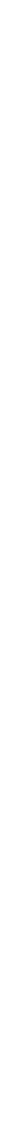

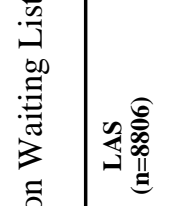

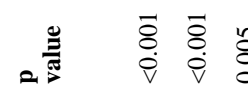

$=\frac{0}{0} \quad \delta$

$\stackrel{0}{0}$

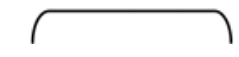

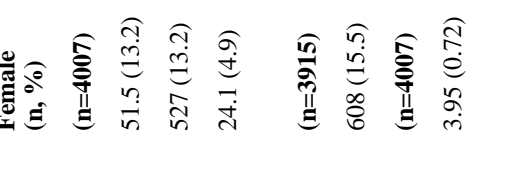

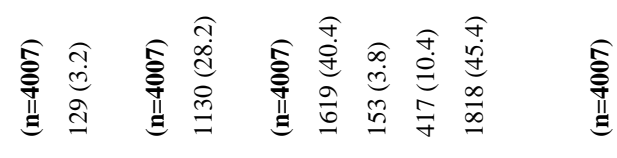

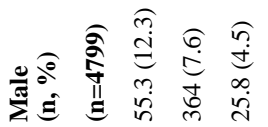

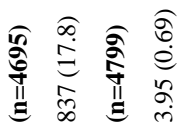

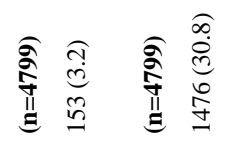

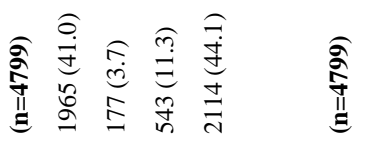

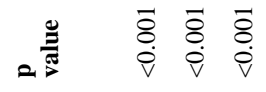

$\begin{array}{ll}\because & \overline{8} \\ 0 & 0 \\ 0 & 0\end{array}$

$\stackrel{\infty}{0} \quad \stackrel{\infty}{\circ}$

$\stackrel{0}{0}$

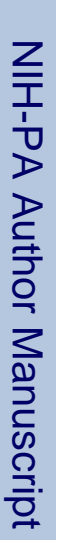

象

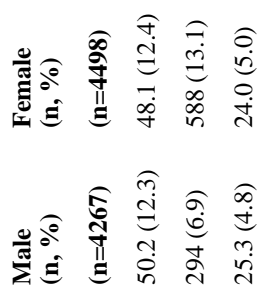

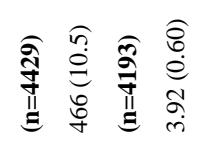

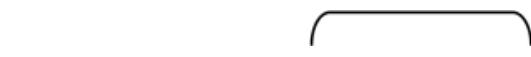

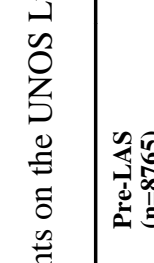

0
0
0
0
0
0
0
0
0
0
0

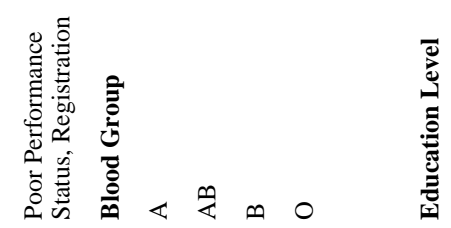


Wille et al.

Page 25

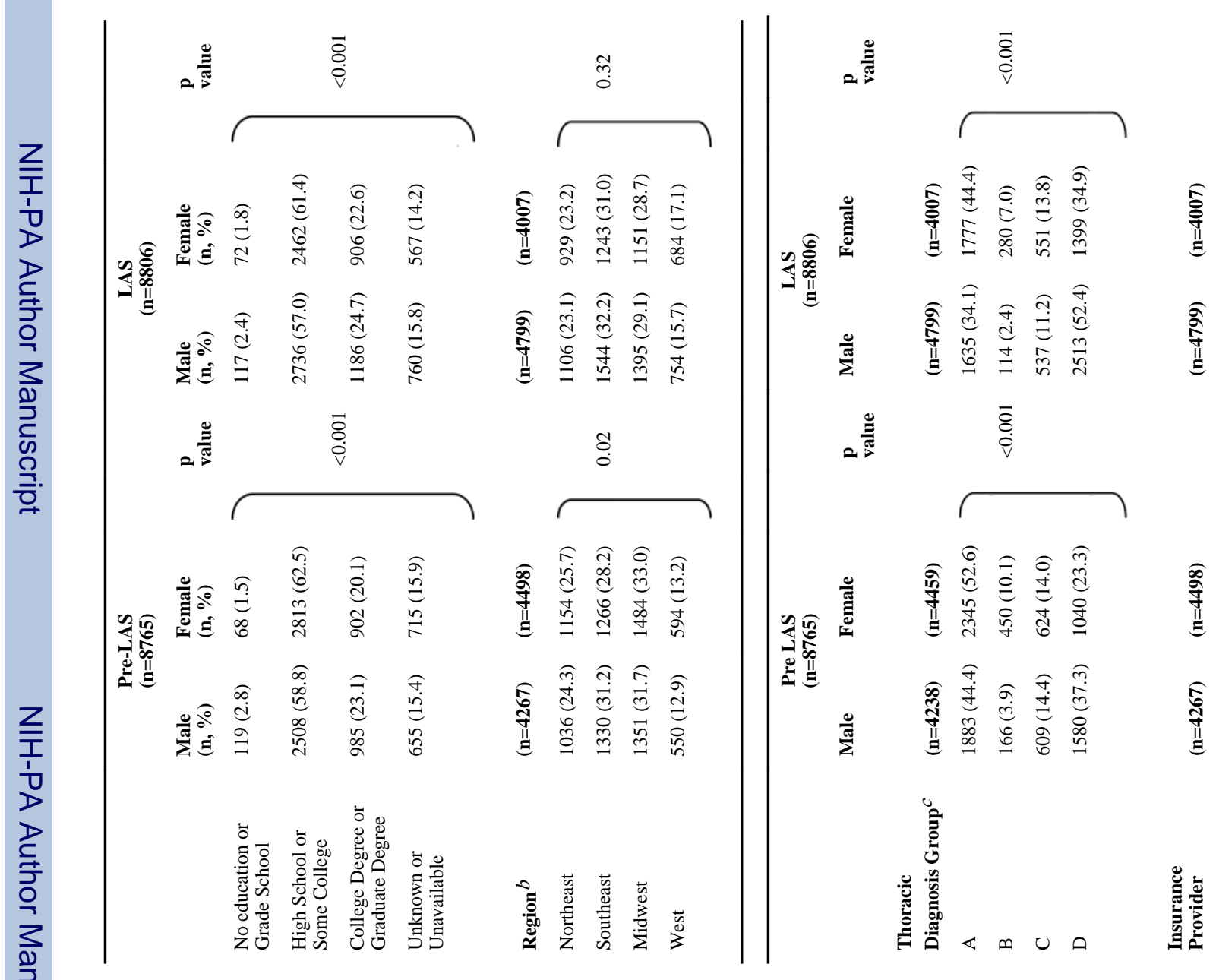




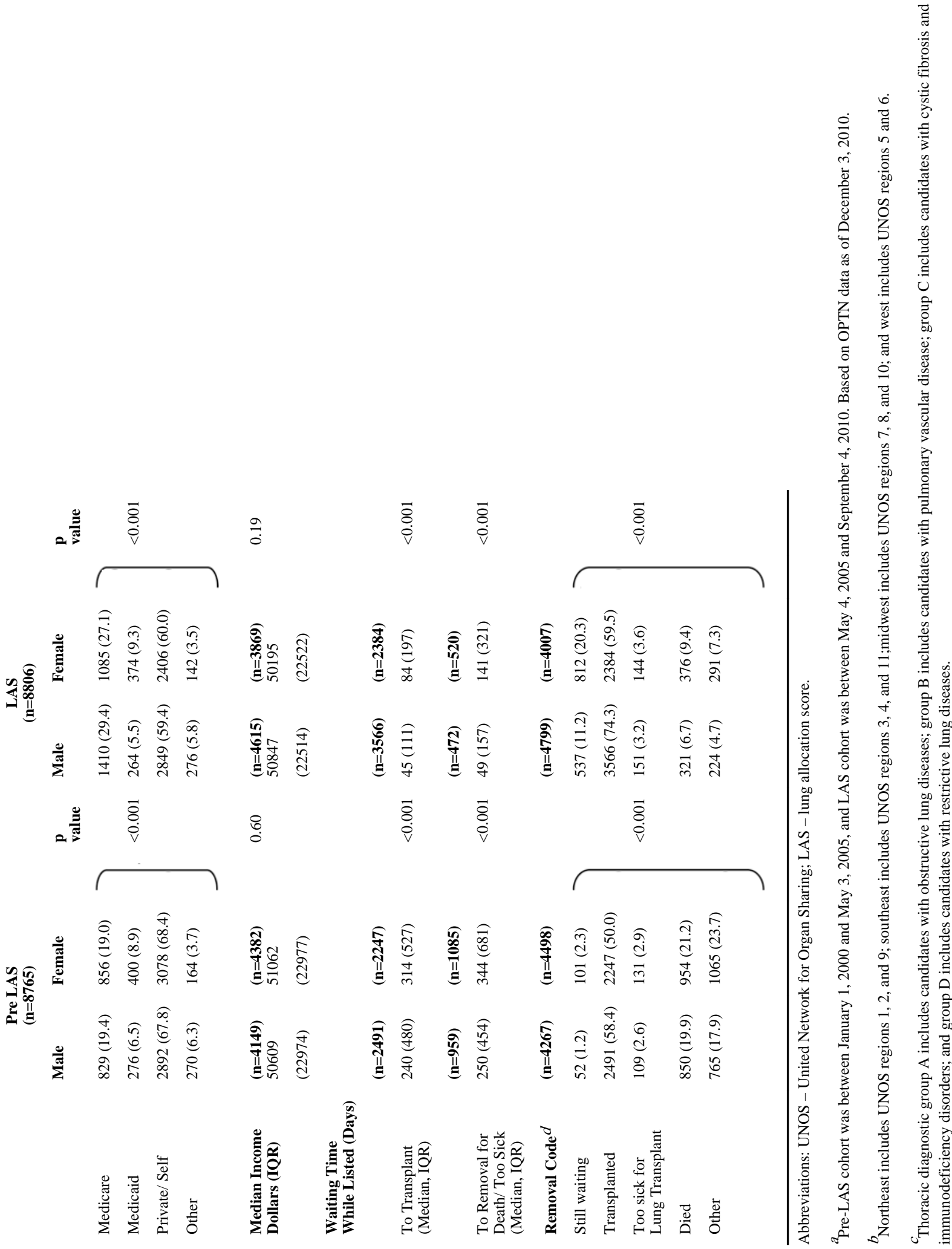

至

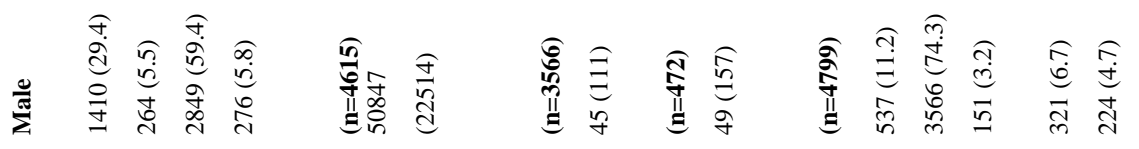

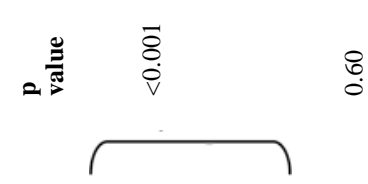

Z 


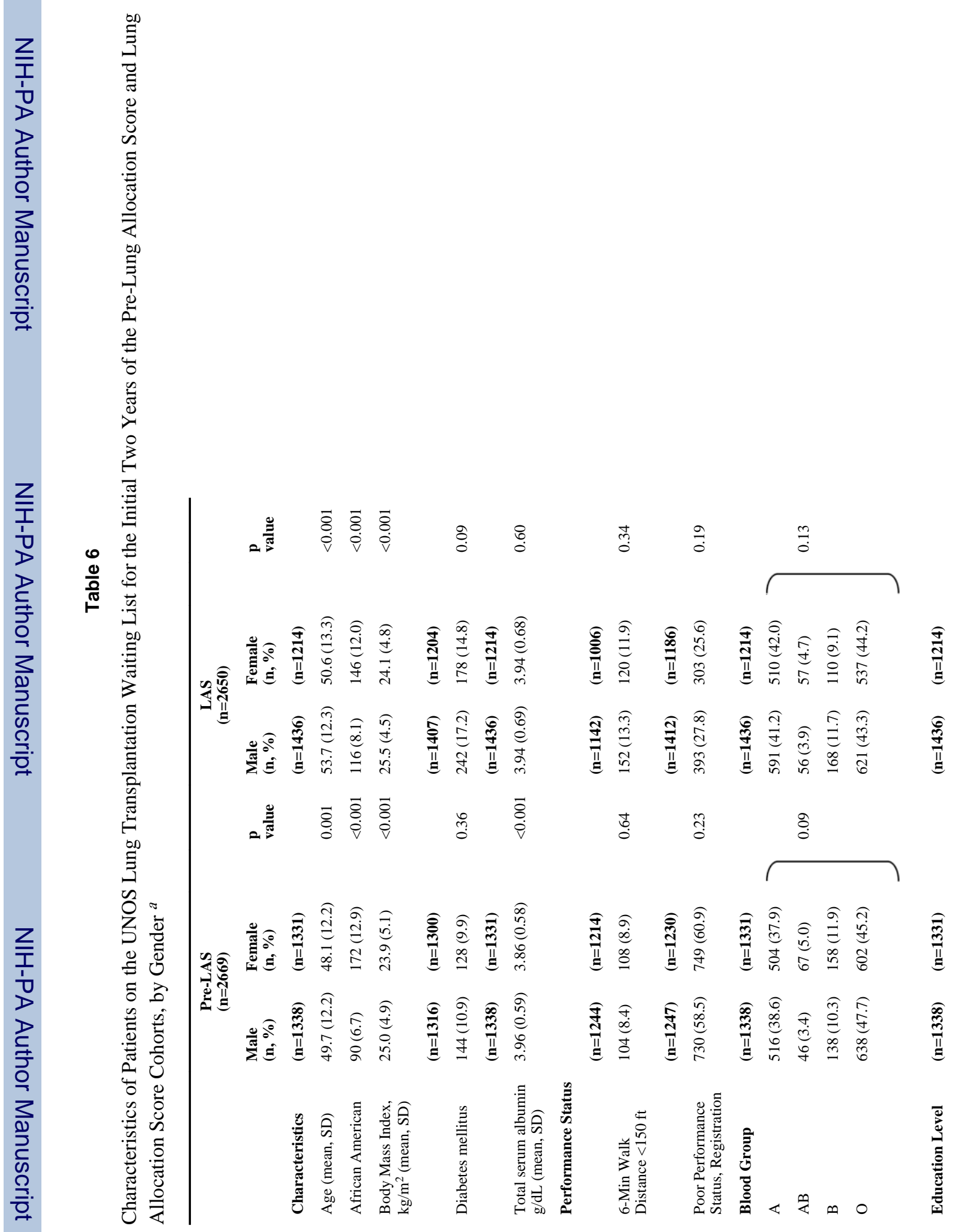




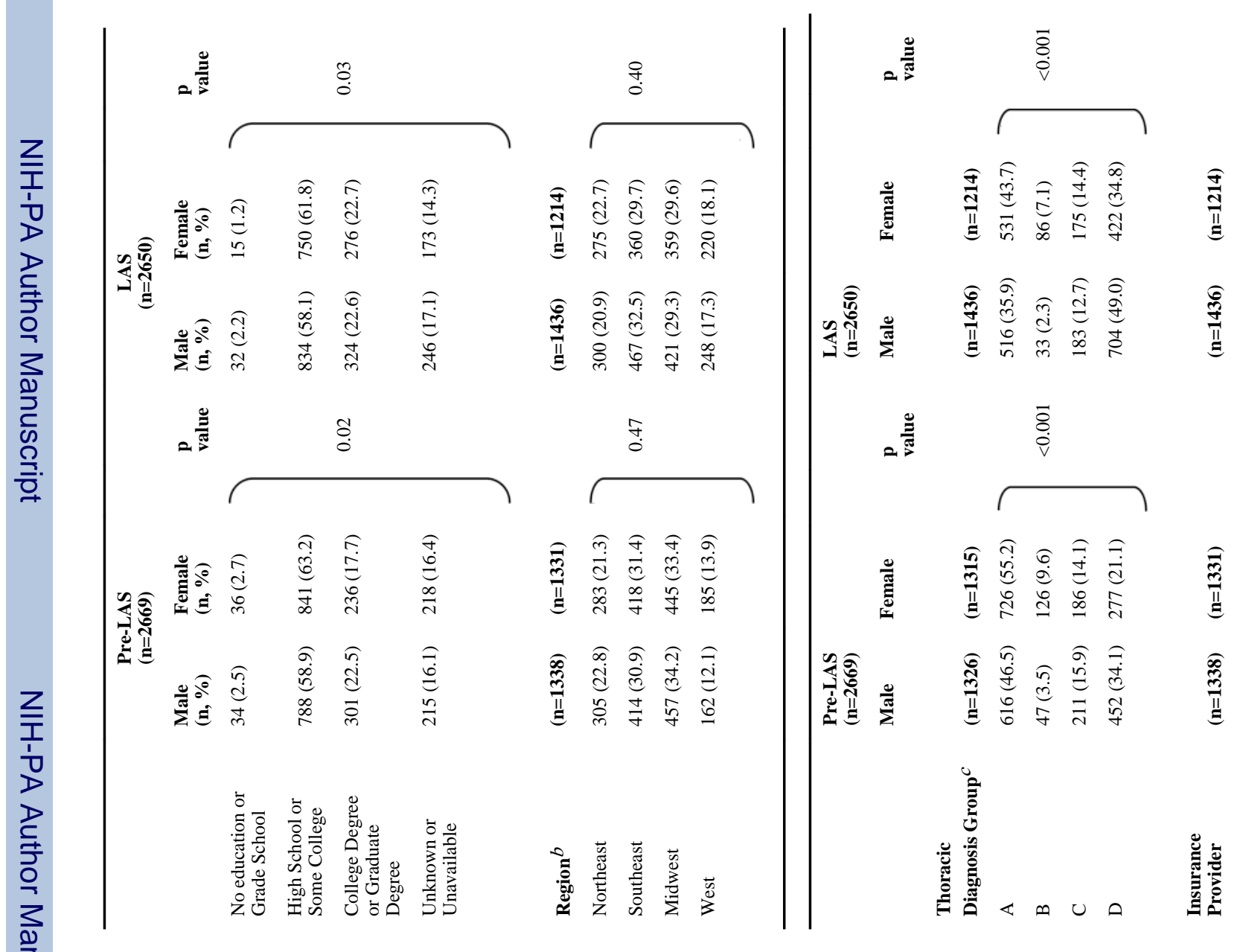


2

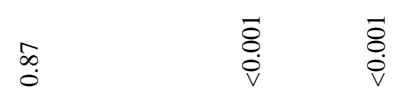

$\underset{\overline{8}}{\dot{v}}$

ș

$\Upsilon$

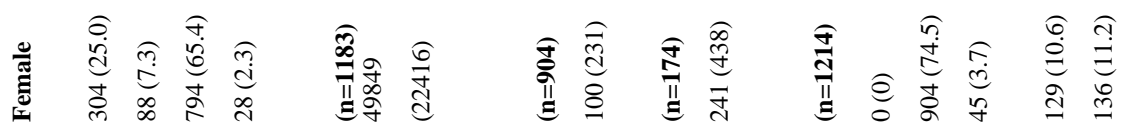

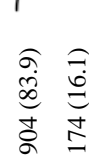

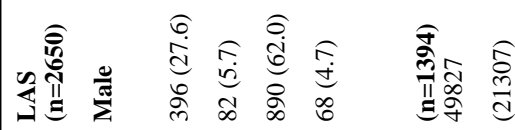

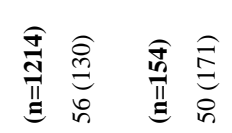

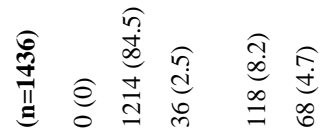

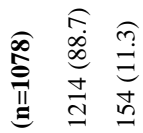

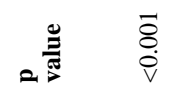

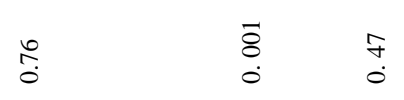
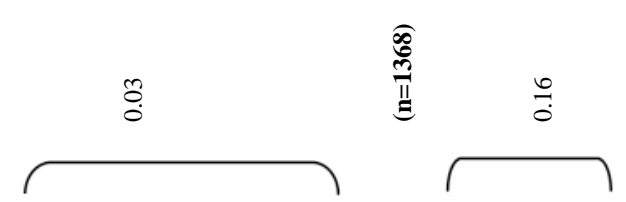

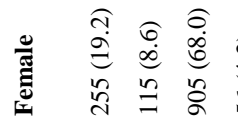

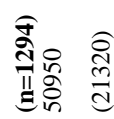

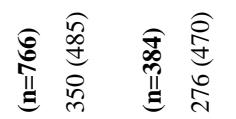

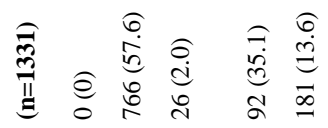

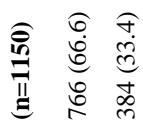

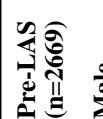

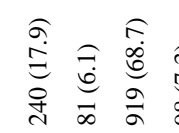

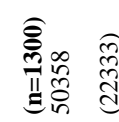

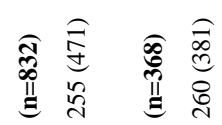

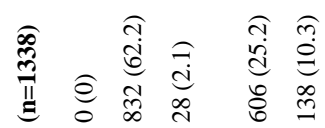

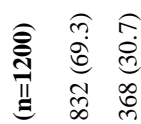

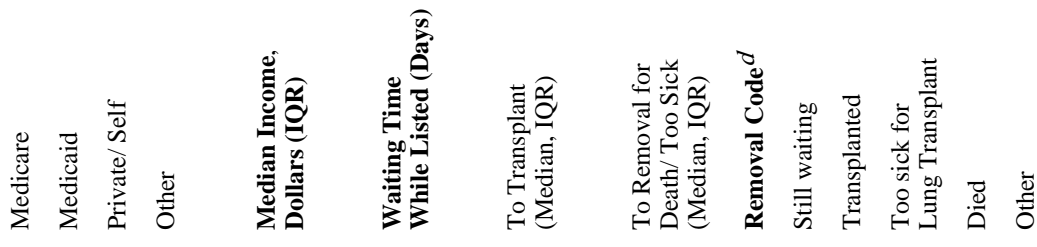

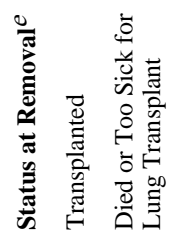

골

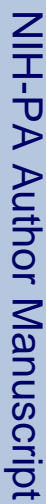

J Heart Lung Transplant. Author manuscript; available in PMC 2014 July 01. 


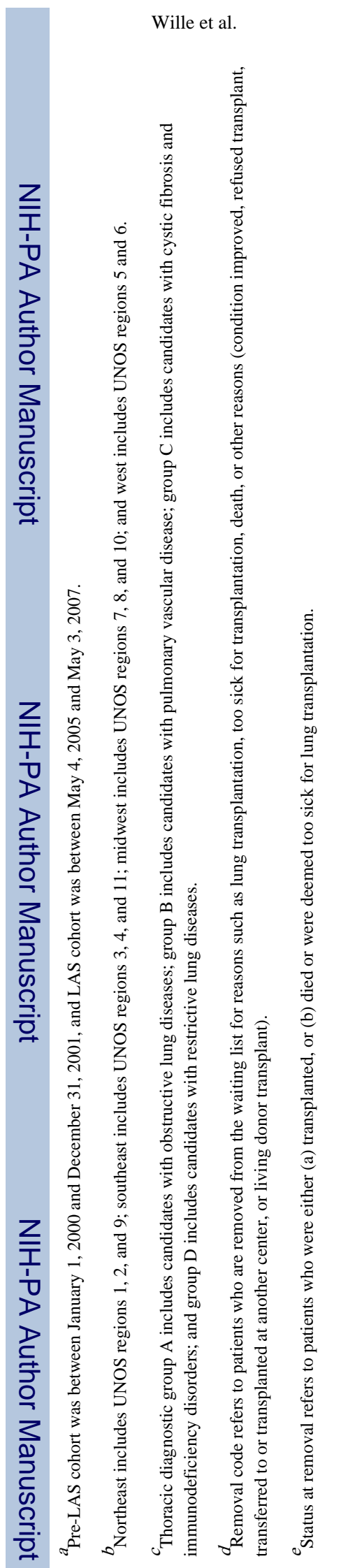

J Heart Lung Transplant. Author manuscript; available in PMC 2014 July 01. 